\section{Pesquisa em saúde e os objetivos do milênio}

Health research and the millennium goals

\section{Ciro Mortella 1}

O trabalho parte do reconhecimento de que saúde leva ao desenvolvimento e não o contrário, minimizando a simultaneidade entre estado da saúde e estado da pobreza. Seguem-se outros argumentos que apontam as razões para um esforço planetário pró-saúde: a) países ricos não pesquisam doenças dos pobres; $b$ ) a dificuldade de acesso dos menos favorecidos a medicamentos e a diagnósticos, apontando como responsáveis as falhas do mercado; c) a fuga de cérebros dos países pobres, entre outros pontos.

A partir deste quadro, o autor justifica os objetivos - claramente meritórios - das Nações Unidas.

Carlos Morel defende, então, políticas de pesquisa coordenadas com ações práticas, de maneira a maximizar a eficácia. Como sugestão, propõe que a pesquisa faça parte da política nacional de saúde, ordenando-se, assim, prioridades, padrões de pesquisa e estímulos à investigação. Critica a falta de aporte de recursos, no Brasil, mencionando que a maioria dos recursos para pesquisa é gerada internamente. Nesse sentido, sugere associação com o capital externo, inclusive para pesquisas estratégicas (comparadas com aquelas voltadas para o curto prazo). Em seguida, trata de prioridades para pesquisa, mediante a categorização das doenças (em três categorias). $\mathrm{O}$ texto termina com uma sugestão para uma ação governamental mais bem definida (no âmbito orçamentário e no de planejamento plurianual).

Em resumo, reitera a importância do Estado como indutor da pesquisa na área de saúde.

Os fatos apresentados são conhecidos: iniqüidade social e inércia de soluções. $\mathrm{O}$ autor assume que o elemento indutor preponderante é a determinação do Estado. Com isto, há uma simplificação dos problemas.

A determinação do Estado, como realizador, esbarra na indisponibilidade de recursos.

Seria necessário aprofundar os elementos jurídicos, fiscais e institucionais que mereceriam ser debatidos para uma mudança. Neste âmbito, há desde procedimentos burocráticos que entravam a pesquisa até preconceitos protecionistas sobre o comando das pesquisas. Estes são temas delicados, para os quais a grandeza dos objetivos - sempre meritórios - não foi suficiente para sensibilizar uma mudança.

O texto não detalha as relações entre a iniciativa privada e os organismos indutores, assim como não faz uma análise mais aprofundada de como a iniciativa privada se insere nas prioridades em saúde que determinam a política pública articulada.

Valeria uma reflexão sobre os dados de pesquisa em saúde realizada pela iniciativa privada no Brasil, em comparação com outros países desenvolvidos e em desenvolvimento, como a Coréia.

Uma análise comparativa dos orçamentos de organismos públicos, como o Ministério da Ciência e Tecnologia, e dos investimentos privados também seria muito esclarecedora.

Também é necessário indagar por que os investimentos privados em pesquisa no Brasil encontram-se nos níveis atuais e não em outros e qual a real possibilidade de se articularem políticas indutoras de prioridades em saúde, sem uma política mais ampla de estímulo à pesquisa e tecnologia voltada ao desenvolvimento econômico.

\section{Os dilemas do desenvolvimento científico e tecnológico brasileiro}

The dilemmas of the Brazilian scientific and technological development

\section{Cristovam Wanderley Picanço Diniz ${ }^{2}$}

Das palavras-chave às referências bibliográficas, "A pesquisa em saúde e os objetivos do milênio: desafios e oportunidades globais, soluções e políticas nacionais", do dr. Carlos Morel, carrega o exercício reflexivo do cientista, a perspectiva organizacional do administrador e o choque de realidade do formulador de políticas. Aponta oportunidades em meio às nossas fragilidades, e metodologias coletivas em meio às nossas iniciativas isoladas para perseguir o que ele denomina de salto científico-tecnológico-sanitário que os países necessitam para atingir os Objeti-

\footnotetext{
1 Federação Brasileira da Indústria Farmacêutica.

c.mortella@febrafarma.org.br
}

\footnotetext{
2 Departamento de Morfologia da UFPA. cwpdiniz@ufba.br
} 